\title{
Theoretical And Experimental Research On 3D Ultrasonic Vibration-Assisted Turning Driven By a Single Actuator
}

\author{
Shiyu Wei \\ Northeastern University \\ Ping Zou ( $\triangle$ pzou425@163.com ) \\ Northeastern University \\ Jiahao Zhang \\ Northeastern University \\ Jingwei Duan \\ Northeastern University \\ Rui Fang \\ Northeastern University
}

\section{Research Article}

Keywords: 3D ultrasonic vibration-assisted turning, Single actuator, Surface topography, Theoretical analysis

Posted Date: November 30th, 2021

DOI: https://doi.org/10.21203/rs.3.rs-1085886/v1

License: (c) (i) This work is licensed under a Creative Commons Attribution 4.0 International License. Read Full License 


\title{
Theoretical and experimental research on 3D ultrasonic vibration-assisted
}

\author{
turning driven by a single actuator
}

\author{
Shiyu Wei Ping Zou* Jiahao Zhang Jingwei Duan Rui Fang \\ School of Mechanical Engineering and Automation, Northeastern University, Shenyang 110819 \\ *Corresponding Author. \\ E-mail address:pzou@mail.neu.edu.cn(P.ZOU)
}

\begin{abstract}
In this paper, the peak heights of several turning methods were analyzed theoretically. Based on the results of theoretical analysis, a 3D-UVAT device driven by a single actuator was developed. To validate this design, the theory and experiment of 3D-UVAT have been undertaken. The FEA results show that design is safe, and can achieve obvious displacements in $\mathrm{X}$-axis, Y-axis, and Z-axis. In the experiment, 304 stainless steel was chosen as experimental material. For comparison, CT, UVAT, and UEVT experiments were also carried out. The experimental results show that with the help of ultrasonic vibration, the surface grooves and defects are significantly reduced. This phenomenon is more obvious on machined surface obtained by 3D-UVAT. Threedimensional surface topography shows that the roughness value $S_{a}$ obtained by 3D-UVAT is smaller than CT and UVAT. Under some cutting conditions, the roughness value $S_{a}$ of machined surface obtained by 3D-UVAT is smaller than UEVT. Thus, the results of theory and experiment proved that the 3D ultrasonic vibration-assisted turning driven by a single actuator has a great potential in improving the quality of machined surface.
\end{abstract}

Key words : 3D ultrasonic vibration-assisted turning; Single actuator; Surface topography; Theoretical analysis.

\section{Introduction}

In recent decades, with the development of manufacturing technology and materials science, the difficult-to-cut materials with superior performance high hardness, high wear, and temperature resistance are widely used [1]. The traditional machining methods are sometimes difficult to satisfy the needs of today's advanced materials. The ultrasonic vibration-assisted turning technology is a machining method that combines traditional turning and ultrasonic vibration, which can reduce cutting force [2-4], decrease cutting heat [5-7], and improve surface quality [8-10] of the workpiece. The ultrasonic vibration turning includes line ultrasonic vibration turning, two-dimensional elliptical ultrasonic vibration turning, and 3D ultrasonic vibration turning, which refers to the vibration pattern during the turning process. The current researches had been verified that many advantages can be achieved by 3D ultrasonic vibration-assisted turning compared with conventional turning [11], line ultrasonic vibration-assisted turning [12], and two-dimensional ultrasonic vibration-assisted turning [13].

Wang [14] developed a 3D ultrasonic elliptical vibration device which was combined onedimensional stepped horn and two-dimensional stepped horn, according to the vibration superposition principle. Different tool nose trajectories can be obtained by adjusting the vibration parameters during the turning process. Building on the research of $\mathrm{Lin}$ [15], $\mathrm{Lu} \mathrm{[16]} \mathrm{described} \mathrm{a} \mathrm{3D}$ elliptical vibration-assisted cutting device, which was driven by four parallel piezoelectric ceramic plates. During the cutting process, four piezoelectric stacks can generate high-frequency vibration after receiving the control signal. The superposition of the four high-frequency vibration signals will cause the tool nose to generate a high-frequency elliptical orbit. As for the development of nonresonant 3D elliptical vibration-assisted turning apparatus, some scholars presented the structure 
based on flexure hinge driven by piezoelectric stacks [17-18]. In these devices, the flexure hinges were utilized to increase the output displacement of turning tool. Cui [19] proposed a method of 3D ultrasonic vibration-assisted cutting device, driven by three parallel piezoelectric ceramics. The vibration signal is generated by three parallel piezoelectric ceramics and transmitted to diaphragm platform. Driven by the diaphragm platform, the tool generated a 3D vibration trajectory. $\mathrm{Lu} \mathrm{[20]}$ developed a resonant T-shaped hinge 3D ultrasonic vibration turning structure, which is driven by three groups of piezoelectric ceramics. The trajectory can be adapted depending on demand. Kurniawan and Hosseinabadi [21,22] developed a 3D ultrasonic elliptical vibration device that was composed of a longitudinal sandwich piezoelectric ceramic and two bending piezoelectric ceramics. During turning process, three groups of piezoelectric ceramics have similar resonance frequencies to realize the three-dimensional curved surface vibration trajectory of turning tool.

To sum up, the current 3D ultrasonic vibration-assisted turning mechanism faces three vital problems. First, large number of compliant linkages and complicated structures were designed to isolate input motions, which may lead to slow response speed because of heavy moving inertia and over-sized dimensions. Second, most 3D ultrasonic vibration-assisted turning mechanisms required two or more ultrasonic actuators. Third, the working conditions of horns are special, that is, the same working frequency. To solve the problems mentioned above, a novel 3D ultrasonic vibrationassisted turning system was proposed. The objective of this paper is to characterize a new 3D-UVAT (Three-dimensional ultrasonic vibration-assisted turning) driven by a single actuator. Simulation and comparison experiment are also submitted to validate the satisfaction of this turning system.

\section{Theoretical analysis}
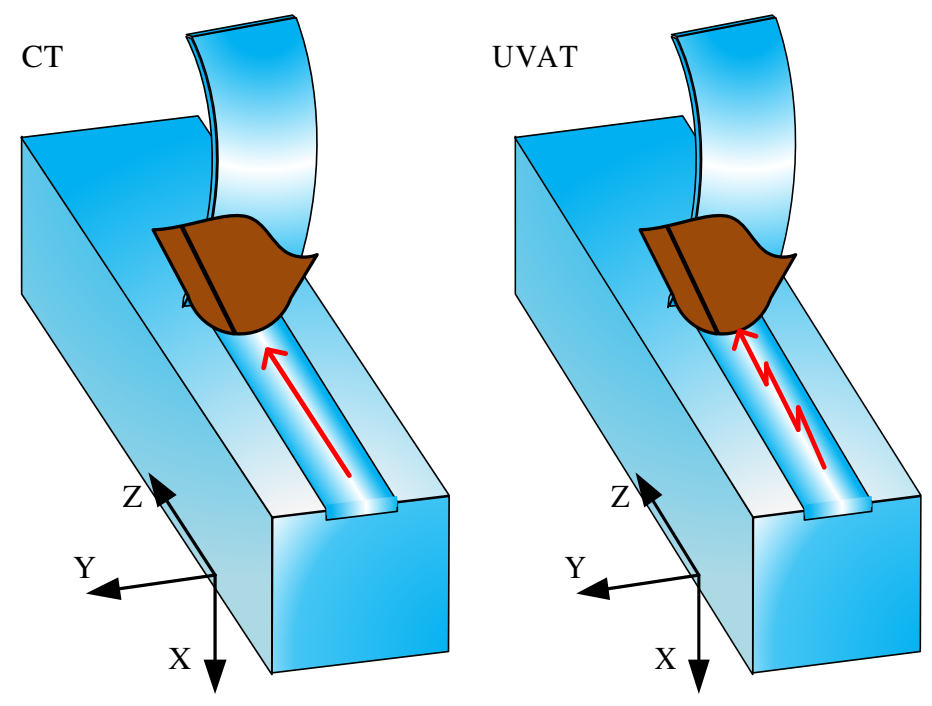

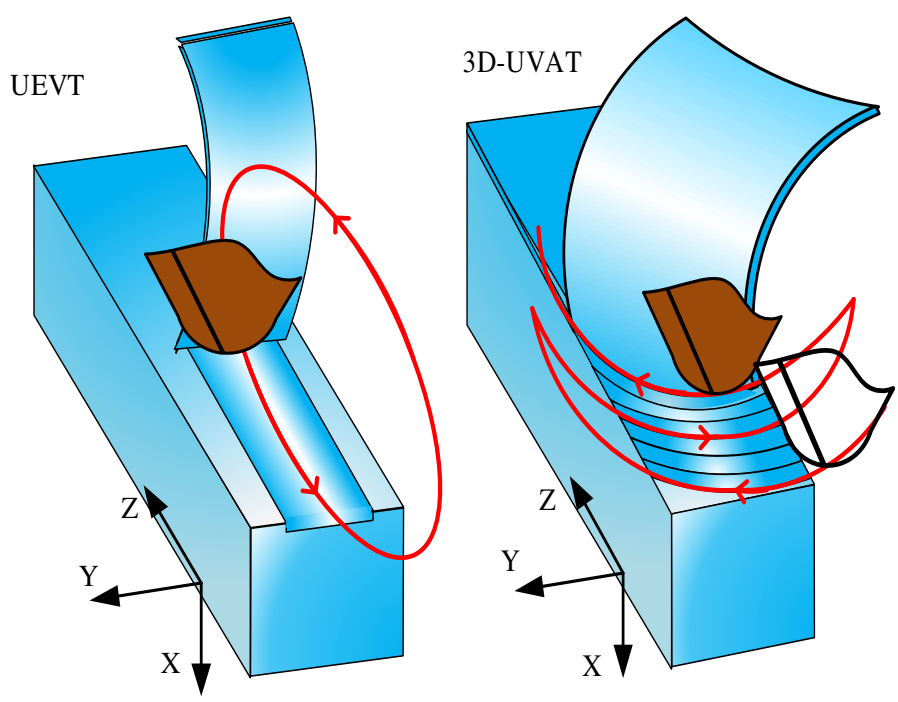

Fig. 1 Schematic of four turning methods

The schematic diagrams of the four turning methods are indicated in Fig. 1, which are CT (Common turning), UVAT (Ultrasonic vibration-assisted turning), UEVT (Ultrasonic ellipseassisted turning) and 3D-UVAT. In order to compare several turning methods, some theoretical analysis was carried out.

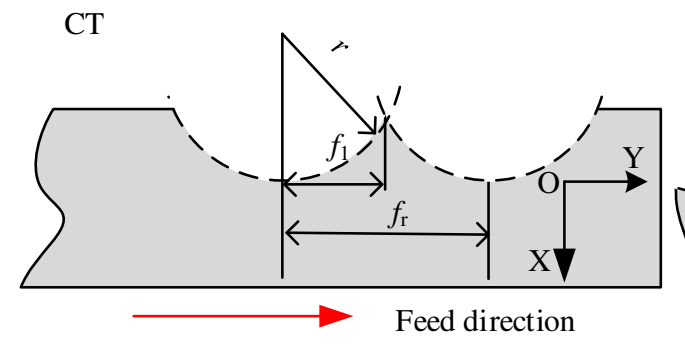

(a)

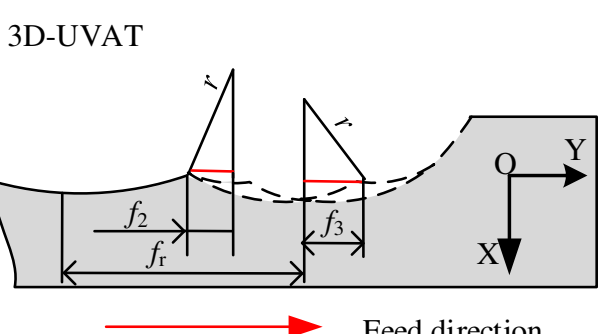

(b)

Fig. 2 The surface residual height obtained by CT and 3D-UVAT

Turning process is actually under the squeezing of turning tool, the surface material of workpiece undergoes deformation, and is separated from the workpiece. The topography of machined surface is related to various parameters, such as turning tool nose radius, feed rate, and so on. Fig. 2(a) is schematic diagram of the maximum residual height of machined surface obtained by CT.

$$
H_{1}=r-\sqrt{r^{2}-f_{1}^{2}}=r\left[1-\sqrt{1-\left(\frac{f_{1}}{r}\right)^{2}}\right]
$$

In the above equation, $H_{1}$ refers to the maximum residual height of workpiece surface obtained by 3D-UVAT $(\mu \mathrm{m}) ; r$ refers to the turning tool nose $(\mu \mathrm{m})$. The $H_{1}$ further calculated as:

$$
H_{1} \approx r \cdot \frac{f_{1}^{2}}{2 r^{2}}=\frac{f_{1}^{2}}{2 r}
$$

The ultrasonic vibration-assisted turning is different from common turning. Ultrasonic vibration-assisted turning has changed the working mechanism of turning process and has a positive effect on improving surface quality of workpiece. Fig. 2(b) is the schematic diagram of the maximum residual height of machined surface by 3D-UVAT. 


$$
H_{2}=r-\sqrt{r^{2}-f_{2}^{2}}+r-\sqrt{r^{2}-f_{3}^{2}}
$$

Where $\mathrm{H}_{2}$ refers to the maximum residual height of workpiece surface obtained by 3D-UVAT ( $\mu \mathrm{m})$. The $\mathrm{H}_{2}$ further calculated as:

$$
H_{2} \approx \frac{f_{2}^{2}}{2 r}+\frac{f_{3}^{2}}{2 r}=\frac{f_{2}^{2}+f_{3}^{2}}{2 r}
$$

In order to compare $H_{1}$ and $H_{2}$, the relationship between them can be expressed by the following formula:

$$
\begin{gathered}
\Delta H=H_{1}-H_{2}=\frac{f_{1}^{2}}{2 r}-\frac{f_{2}^{2}}{2 r}-\frac{f_{3}^{2}}{2 r} \\
f_{1}=\frac{f_{r}}{2}=f_{2}+f_{3} \\
\Delta H=\frac{\left(f_{2}+f_{3}\right)^{2}}{2 r}-\frac{f_{2}^{2}}{2 r}-\frac{f_{3}^{2}}{2 r}=\frac{f_{2} \cdot f_{3}}{r}>0
\end{gathered}
$$

According to Eq. (7), within a certain range, the difference between $H_{1}$ and $H_{2}$ is always greater than zero. In other words, the maximum residual height of machined surface obtained by CT is greater than 3D-UVAT. The reduction of surface residual height is conducive to reduce surface roughness.

UVAT

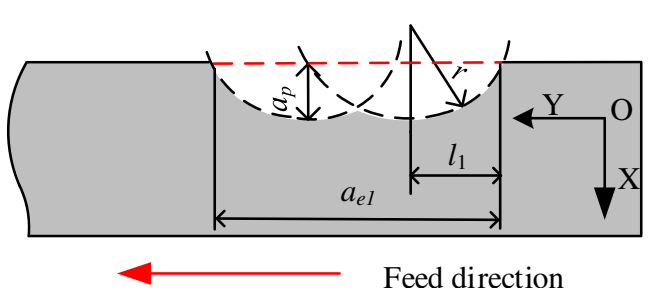

(a)

\section{D-UVAT}

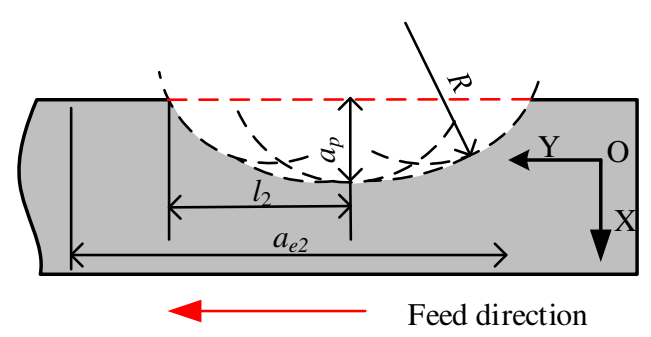

(b)

Fig. 3 Comparison chart of turning width of UVAT and 3D-UVAT

Fig. 3 is schematic diagram of turning width of UVAT and 3D-UVAT. In Fig. 3(a), regardless of turning tool wear and other factors, turning width of UVAT can be calculated by the following formula.

$$
\begin{gathered}
a_{e 1}=S+2 l_{1} \\
S=\frac{n F_{r}}{60 f} \\
2 l_{1}=2 \sqrt{r^{2}-\left(r-a_{p}\right)^{2}}
\end{gathered}
$$

Where $a_{e 1}$ stand for turning width of UVAT $(\mu \mathrm{m}) ; r$ represents turning tool nose radius (mm); $S$ means advancing length of turning tool nose in one vibration cycle $(\mu \mathrm{m}) ; a_{p}$ is cutting depth $(\mathrm{mm})$; $F_{r}$ indicates feed $(\mathrm{mm} / \mathrm{r}) ; n$ stand for speed of the lathe spindle $(\mathrm{r} / \mathrm{min}) ; f$ is vibration frequency $(\mathrm{Hz})$. 
The turning width of 3D-UVAT shown in Fig. 3(b).

$$
\begin{gathered}
a_{e 2}=S+2 l_{2} \\
2 l_{2}=2 \sqrt{R^{2}-\left(R-a_{p}\right)^{2}} \\
\Delta a_{e}=a_{e 2}-a_{e 1}=2 \sqrt{a_{p}}\left(\sqrt{2 R-a_{p}}-\sqrt{2 r-a_{p}}\right)>0
\end{gathered}
$$

Where $a_{e 2}$ stand for turning width $(\mu \mathrm{m}) ; R$ is the cross-sectional radius of turning belt $(\mathrm{mm})$. When the feed is the same, the larger the turning width, the finer the bulge between two adjacent turning belts. According the above equation, when the feed rate, cutting depth, and ultrasonic vibration frequency are the same, the width of bulge distributed on machined surface obtained by 3D-UVAT is finer. The reduction of bulge width contributes to the reduction of surface roughness.

Most UEVT is equivalent to orthogonal turning, but 3D-UVAT is closer to oblique cutting. Compared with orthogonal cutting, oblique cutting has many advantages. According to Fig. 1, in the process of UEVT, the curl form of chip is closer to the up-curling. However, in the process of 3D-UVAT, the curl form of chips shows obvious lateral-curling. In this case, chips are not only easier to be taken away, but also can prevent the machined surface from being scratched. On the other hand, the lateral outflow of chips helps to reduce the friction resistance between chips and turning tool. The reduction of friction resistance is helpful to prolong the life of turning tool, reduce the generation of built-up edge, and improve the surface quality of machined workpiece. Fig. 4 is three-dimensional schematic diagram of machined surface obtained by UEVT and 3D-UVAT.

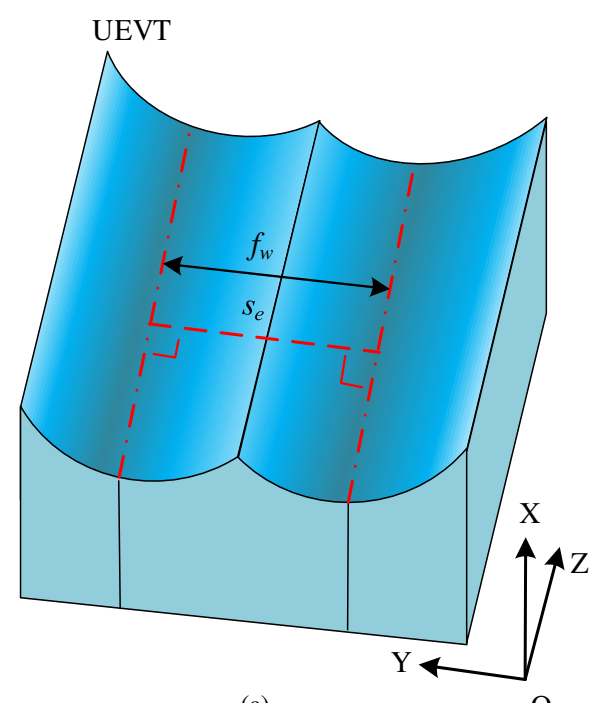

(a)

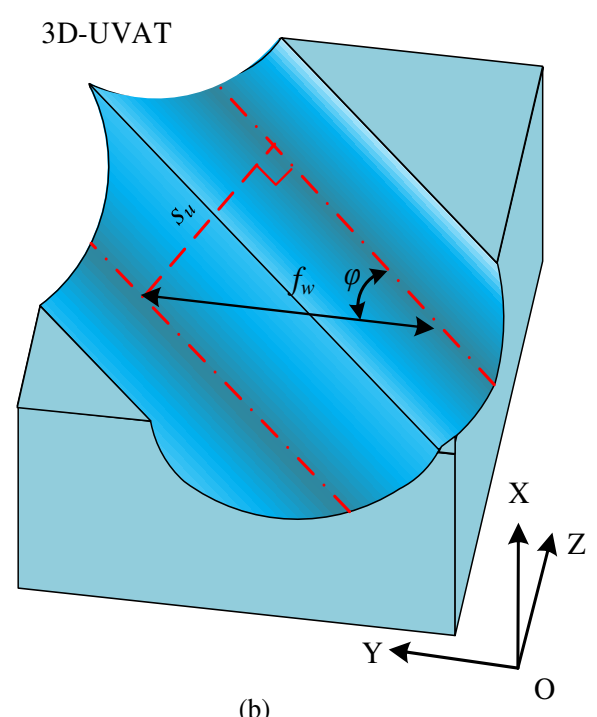

(b)

Fig. 4 Three-dimensional schematic diagram of surface residual height

During UEVT process, the turning belt is perpendicular to feed direction. This turning method has many similarities with CT. However, in 3D-UVAT process, there is an acute angle between the turning belt and feed direction. Fig. 5 is the cross-sectional view of two machined surfaces. 


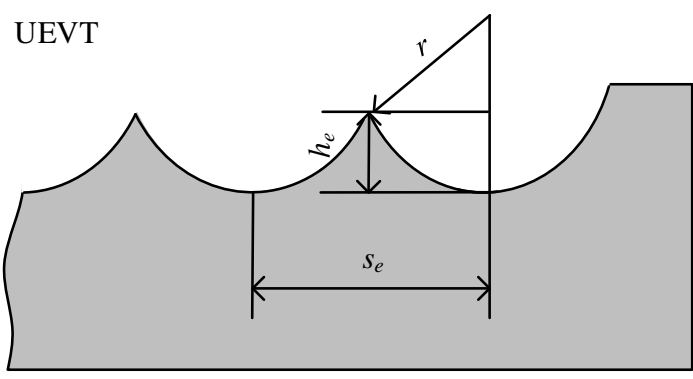

(a)

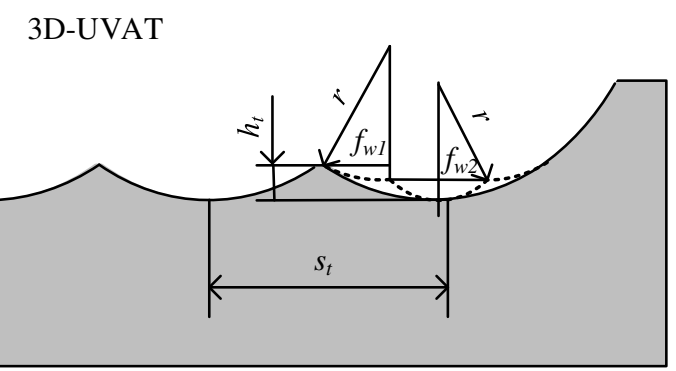

(b)

Fig. 5 The cross-sectional view of turning belt

$$
\begin{gathered}
h_{e}=r-\sqrt{r^{2}-\left(\frac{s_{e}}{2}\right)^{2}}=\frac{s_{e}{ }^{2}}{8 r} \\
s_{e}=f_{w}
\end{gathered}
$$

Where $h_{e}$ is peak height of machined surfaces obtained by UEVT $(\mu \mathrm{m}) ; s_{e}$ represents the width of turning belt produced by UEVT in a cutting cycle $(\mathrm{mm}) ; f_{w}$ represents the feed of turning tool in Y-axis direction in a vibration period $(\mathrm{mm})$, which can be expressed by

$$
\begin{gathered}
f_{w}=n F_{r} / 60 f \\
h_{t}=2 r-\sqrt{r^{2}-f_{w 1}^{2}}-\sqrt{r^{2}-f_{w 2}^{2}} \\
f_{w 1}+f_{w 2}=\frac{1}{2} s_{t}=\frac{1}{2} f_{w} \sin \theta \\
\Delta h=h_{e}-h_{t}=\frac{f_{w}{ }^{2}}{8 r}-\frac{\left(f_{w} \sin \theta\right)^{2}-8 f_{w 1} f_{w 2}}{8 r} \geq 0
\end{gathered}
$$

In the above formula, $h_{t}$ is peak height of machined surfaces obtained by 3D-UVAT $(\mu \mathrm{m}) ; s_{t}$ represents the turning belt width produced by 3D-UVAT in a turning cycle $(\mu \mathrm{m})$. According to Eq. (19), compared with UEVT, 3D-UEVT can obtain a smaller peak-valley height under the same turning conditions.

According to the calculation principle of surface roughness, the reduction of peaks-valley height and bulge width help to reduce roughness of machined surface. From the above analysis, it can be concluded that compared with CT, UVAT and UEVT, 3D-UVAT is more friendly in improving the machined surface quality.

\section{Design of 3D-UVAT system}

The 3D-UVAT system driven by a single actuator is composed of several elements: the ultrasonic vibration actuators, the vibration-carrying rod with spiral grooves, holder, and several plates, as indicated in Fig. 6. 


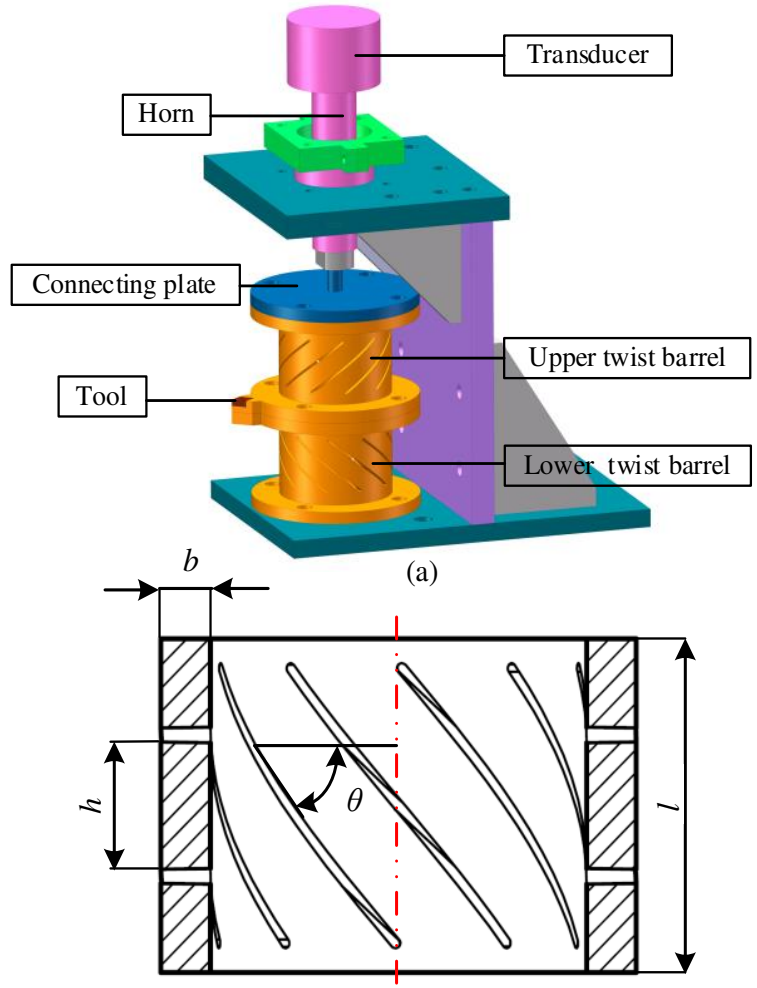

(c)

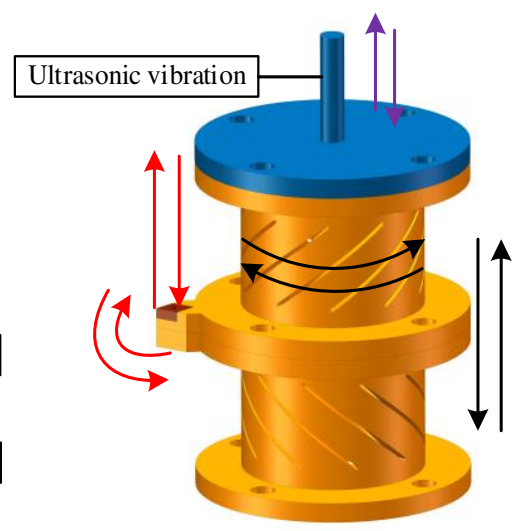

(b)

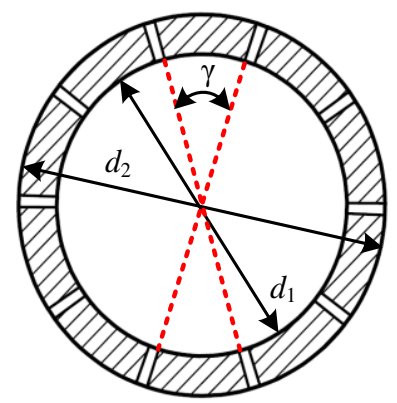

(d)

Fig. 6 Schematic of 3D ultrasonic vibration-assisted turning system

The role of ultrasonic vibration actuator is to convert the high-frequency electrical signal into mechanical vibration signals and transmit it. It includes two parts: a transducer and a horn. The vibration-carrying rod with spiral grooves is used to transmit the ultrasonic vibration signals from ultrasonic vibration actuator to turning tool holder. The connecting plate is used to connect the horn and vibration-carrying rod with spiral grooves. Another function of the connecting plate is to transmit vibration signals to vibration-carrying rod. The horn is fixed on the support plate.

The vibration-carrying rod with spiral grooves is an important part to realize $3 \mathrm{D}$ curved trajectory of turning tool. It composes of connecting plate and twists barrels. The realization of 3D curved surface trajectory of turning tool is excited by a set of ultrasonic vibration signals. In the displacement output structure, considering the deformation characteristics of spring, two twist barrels were selected. When the twist barrel is stretched and compressed, expansion and torsion deformation will occur, as showing in Fig. 6(b).

Dived vibration-carrying rod into upper twist barrel and lower twist barrel, there are ten righthand spiral grooves arranged on the sidewall of the upper twist barrel. The force acting on the twist barrel is transmitted and decomposed into along tangent direction of the twist barrel and perpendicular to the tangent surface of the spiral grooves. The structure of lower twist barrel is the same as to upper twist barrel, but the spiral grooves rotate in the opposite direction. There is a holder designed on the upper twist barrel to install turning tool.

When the connecting plate is subjected to periodic displacement in the form of sinusoidal, twist barrels will be tensed and compressed follow the movement of connecting plate. When twist barrels are moving, the turning tool will move periodically follow twist barrels in the direction of Z-axis. During telescopic deformation of twist barrels, the turning tool also rotates with twist barrels in the planar of O-XY. Therefore, displacement output in three directions can be achieved by this device. 
In the established coordinate system, turning tool movement trajectory is expressed by mathematical equations. The structure of upper twist barrel shows in Fig. 6(c). It can be seen from the above figure that several spiral grooves divide the whole twist barrel into several rectangular cross-section springs. $l$ refers to the effective length of spring $(\mathrm{m}), d_{2}$ is the outer diameter of spring (m), $d_{1}$ stands for the inner diameter of spring (m), $h$ refers to the width of the spring (m), $b$ is the thickness of spring $(\mathrm{m})$. The deformation of twist barrels divides into torsional deformation in the planar of O-XY and telescopic deformation in the direction of the Z-axis. The stiffness coefficient of spring group formed by several rectangular cross-section springs calculated as:

$$
k=m \frac{G b^{2} h^{2}}{d^{3} n}\left\{\frac{4}{\pi} \times \frac{h}{b}\left[\frac{1}{3}-\frac{64 h}{\pi^{5} b} \sum_{i=1,3,5, \ldots}^{\infty} \frac{i \pi}{2 h} b\right]\right\}
$$

Where, $G$ refers to the modulus of rigidity (MPa); $d=\left(d_{1}+d_{2}\right) / 2$ is the middle diameter of spring (m); $n$ stands for the spring number of active coils. In actual calculations, $i$ only involve the first three. Considering that the Eq. (20) is very complicated, the following simplified formula is used to replace the above formula in general engineering applications.[23]

$$
k=\frac{G h^{4}}{d^{3} n}\left(0.42 \frac{b}{h}-0.25\right)
$$

The cross section of twist barrel is shown in Fig. 6(d). The vibration-carrying rod can be divided into several open thin-walled twist barrels, and the number of which is equal to the number of spiral grooves. The ultrasonic signal transmits to the spiral grooves decomposes into two components, the component force in the tangential direction of the spiral grooves $\left(F_{x}\right)$ and the component force in the direction perpendicular to the spiral grooves $\left(F_{y}\right)$. The thin-walled twist barrel performs torsion in $\mathrm{O}-\mathrm{XY}$ under the $F_{x}$, and its torsion angle $\Delta \varphi$ is expressed as [24]:

$$
\Delta \varphi=\frac{3 T l}{m G c b^{3}}
$$

In the Eq. (22) $c$ corresponds to the effective circumference of thin-walled twist barrel, $T$ refers to torque (N.m), which calculated as:

$$
\begin{gathered}
c=\frac{n \gamma}{360} \times 2 \pi \\
T=F \sin \theta
\end{gathered}
$$

By substituting the Eq. (23) and (24) into Eq. (22), the Eq further calculated as:

$$
\Delta \varphi=\frac{3 F \sin \theta l}{m G c b^{3}}
$$

The movement of turning tool is excited by the ultrasonic vibration signal applied on vibrationcarrying rod with spiral grooves, the relationship between vertical displacement of turning tool and working time can be calculated as:

$$
z(t)=\frac{u(t)}{2}
$$

In the Eq. (26) $U$ is displacement of horn in the vertical direction which can be expressed as:

$$
u(t)=A \cdot \sin \left(2 \pi f t+\phi_{0}\right)
$$


In the Eq. (27) $A$ is vibration amplitude $(\mu \mathrm{m}), f$ refers to the frequency of ultrasonic vibration $(\mathrm{Hz})$, and $\varphi_{0}$ is the initial phase angle of ultrasonic signal.

$$
z(t)=\frac{u(t)}{2}=A \cdot \frac{\sin \left(2 \pi f t+\phi_{0}\right)}{2}
$$

When the ultrasonic vibration signal is transmitted to the spiral grooves, the force is decomposed into a component force $F_{x}(t)$ in the tangential direction of spiral grooves and a component force $F_{y}(t)$ in the direction of perpendicular to spiral grooves, $F_{x}(t)$ is given in the Eq. (29):

$$
F_{x}(t)=F(t) \cdot \sin \theta
$$

In above equation. $F(t)$ calculated by Hooke's law, namely $F=\Delta l \cdot k$.

$$
F(t)=\Delta l \cdot k=u(t) \cdot k
$$

Thus, the $F_{x}(t)$ further expressed as:

$$
F_{x}(t)=A \cdot \sin \left(2 \pi f t+\phi_{0}\right) \cdot k \cdot \sin \theta
$$

In the Eq. (31) $\theta$ is the rise angle of the spiral grooves.

Combining Eq. (31) and Eq. (25), the relationship of torsion angle and time as follows:

$$
\varphi(t)=\frac{6 l}{m G c b^{3}} F_{x}(t)
$$

The above Eq. can be calculated

$$
\varphi(t)=\frac{6 l}{m G c b^{3}} A \cdot \sin \theta \sin \left(2 \pi f t+\phi_{0}\right)
$$

The displacement of the turning tool nose along the $\mathrm{X}$-axis and Y-axis can be calculated by the following:

$$
\begin{gathered}
y(t)=R_{L} \cdot \sin [\varphi(t)] \\
\mathrm{x}(t)=R_{L}-R_{L} \cdot \cos [\varphi(t)]
\end{gathered}
$$

Where $R_{L}$ refers to the distance between turning tool nose and central axis of vibration-carrying rod (m). Eq. (28), (34), and (35) combined with the feed speed of turning tool can be used to describe the 3D surface movement trajectory of turning tool nose.

Combining the size of vibration-carrying rod, the feed rate, the amplitude and frequency of ultrasonic vibration signal, the trajectory of turning tool nose can be got by the MATLAB software is shown in Fig. 7. 


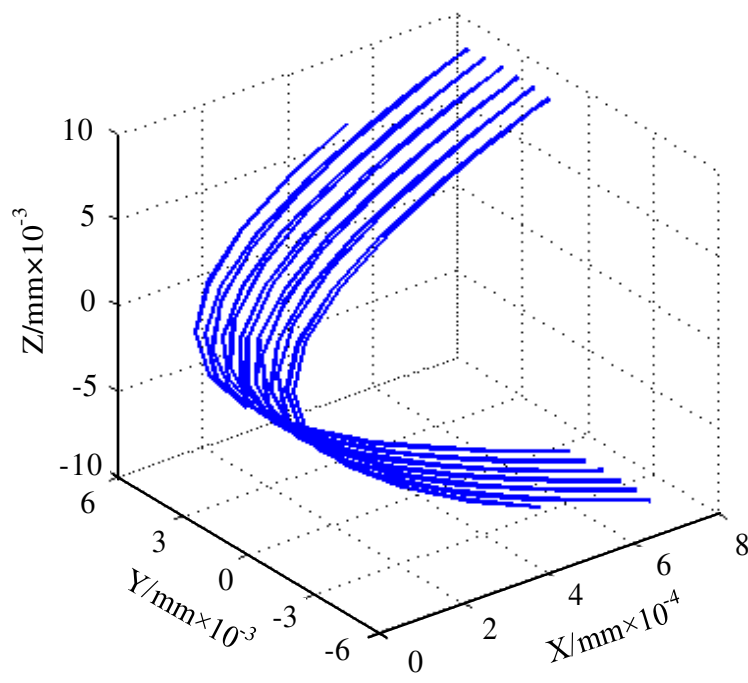

Fig. 7 Tool vibration trajectory of 3D-UVAT

It can be seen from Fig. 7 that the trajectory of turning tool nose is a semi-elliptical 3D space surface. Theoretical calculations can prove that applying a set of ultrasonic vibration signals to this vibration-carrying rod with spiral grooves can realize the $3 \mathrm{D}$ space surface movement of tool nose by a single actuator.

\section{Simulation of vibration-carrying rod with spiral grooves}

During the process of 3D ultrasonic vibration-assisted turning, the movement trajectory and turning quality are related to the vibration-carrying rod with spiral grooves. To further refine the geometrical parameters and verify the performance of vibration-carrying rod, finite element analysis (FEA) was performed.
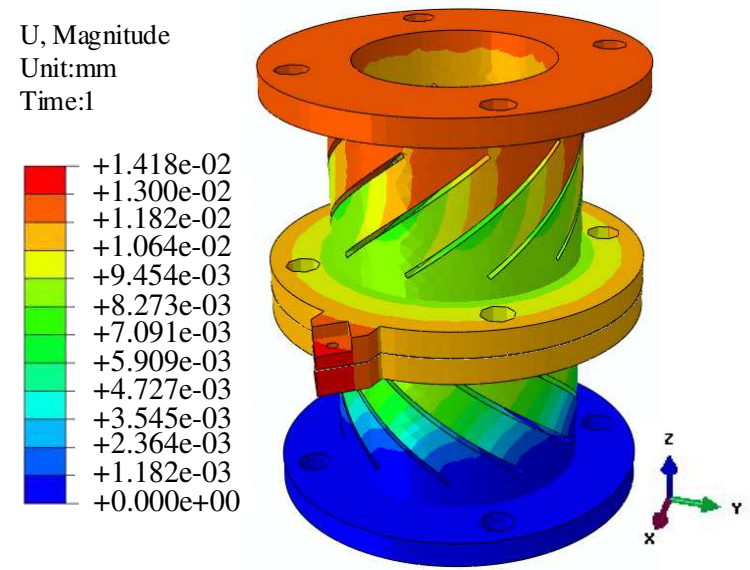

(a) 


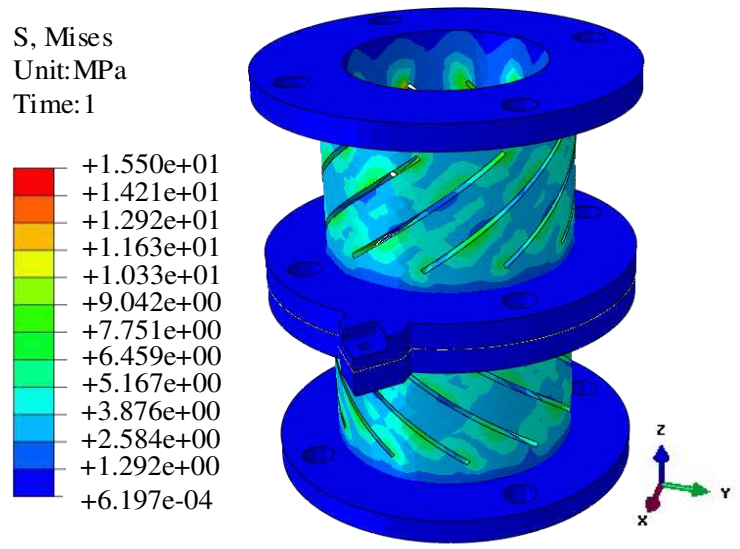

(b)

Fig. 8 The FEA results of the vibration-carrying rod

Fine structure is not only the vibration-carrying rod with spiral grooves can sustain stress but also can produce satisfactory displacement. In the simulation, zero displacements were applied to the fixed platform. Input displacement is assumed $20 \mu \mathrm{m}$ provided by the piezoelectric actuator. Fig. 8 are the FEA results of vibration-carrying rod with spiral grooves. It can be observed that the maximum deformation is about $14 \mu \mathrm{m}$, which occurs at the nose of turning tool. The maximum stress is $15 \mathrm{MPa}$, which occurs at the spiral grooves, far less than the permissible stress range of the material $65 \mathrm{Mn}$ (around $800 \mathrm{MPa}$ ). Thus, the design of 3D-UVAT system is perfectly safe.

The output displacement was extracted for analyses of 3D-UVAT system. Take a node on the turning tool nose, obtain the maximum displacement in the direction of three coordinate axes (X, Y, Z), which are shown in Fig. 9.

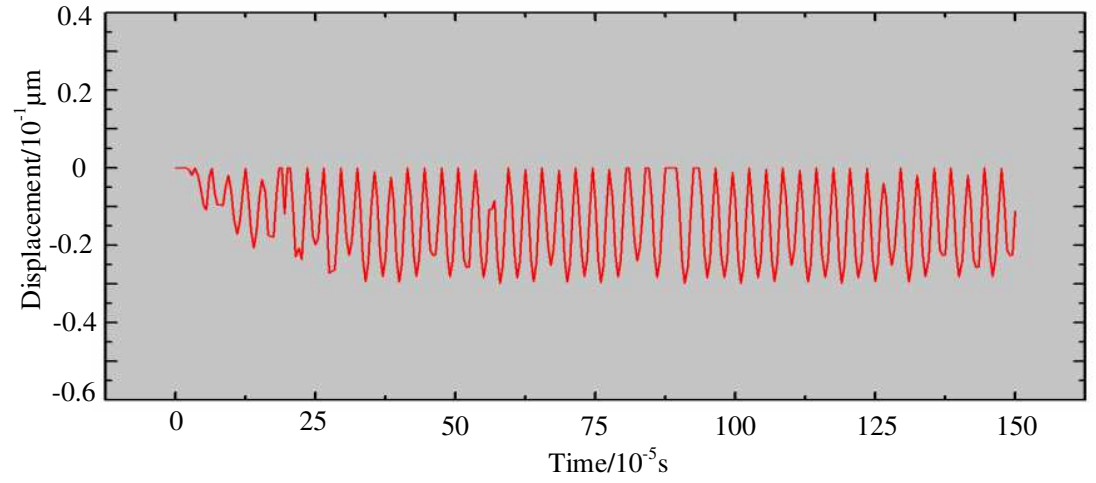

(a)The displacement in the direction of $\mathrm{X}$-axis

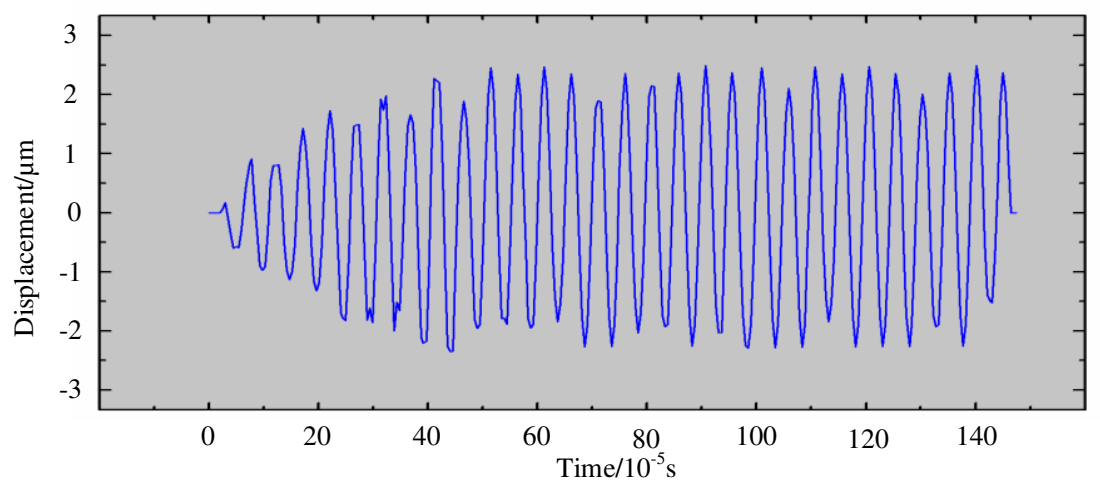

(b)The displacement in the direction of Y-axis 


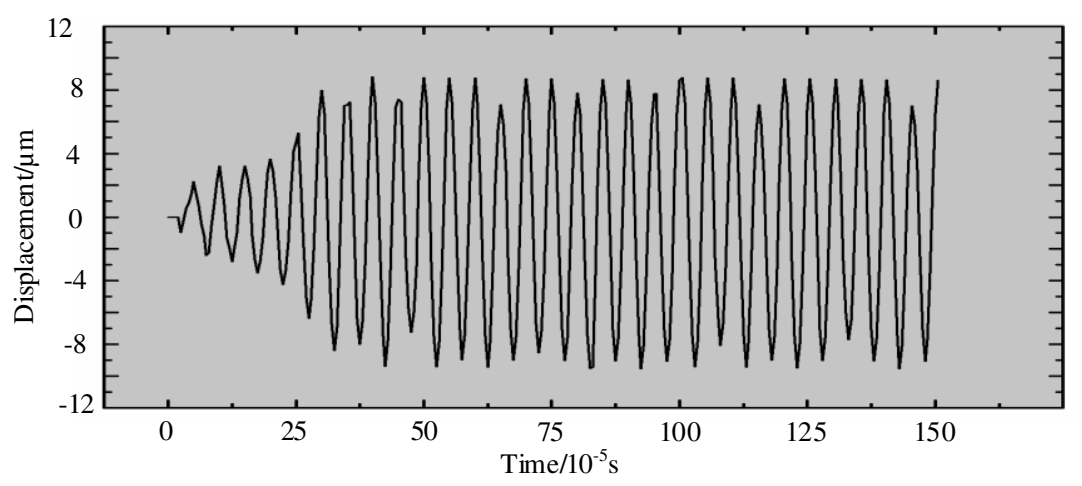

(c)The displacement in the direction of Z-axis

Fig. 9 The displacement in three directions

It can be seen from Fig. 9 that there are obvious displacements in three directions. The maximum displacement in the $\mathrm{X}$-axis direction is about $0.3 \mu \mathrm{m}$, in the Y-axis direction is about $2 \mu \mathrm{m}$, and in the Z-axis direction is about $8 \mu \mathrm{m}$.

\section{Experimental and setups}

After the finite element simulation, the structural parameters of 3D-UVAT system are optimized and determined. To further investigate the performance of the 3D-UVAT device, a series of experiments were conducted to verify its performance. The material of vibration-carrying rod with spiral grooves is $65 \mathrm{Mn}$, and other parts are 45 steel. In the experimental setup, the working frequency of ultrasonic horn is $20 \mathrm{kHz}$. The material of workpiece is 304 stainless steel, which length is $60 \mathrm{~mm}$ and diameter is $35 \mathrm{~mm}$. The raw workpiece surface roughness is $3.2 \mu \mathrm{m}$. The experimental setup is illustrated in Fig. 10.

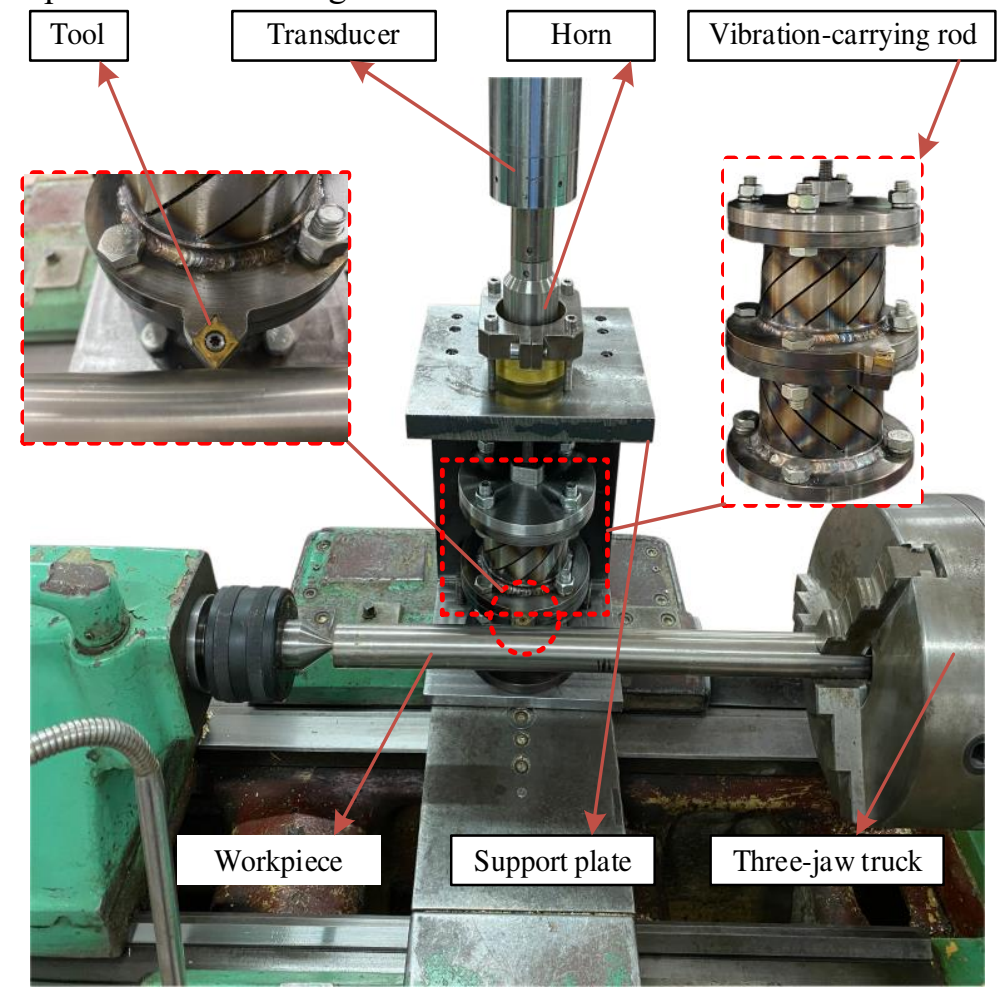

Fig. 10 Experimental system and 3D-UVAT device

The available research conclusions, appropriate cutting speed $\left(v_{c}\right)$, feed rate $\left(f_{r}\right), \operatorname{depth}$ of $\operatorname{cut}\left(a_{p}\right)$ and amplitude of ultrasonic(A) are helpful to improve the quality of machined surface [25-27]. In UEVT process, the amplitude ratio has an important influence on the turning surface. When the amplitude ratio is 0.9 , a better processed surface can be obtained $[28,29]$. For comparison, several 
groups of single-factor experiments were carried out. To eliminate the negative effects of experimental errors on the results, each group of experiments was repeated three times. The experimental conditions are summarized in Table 1.

Table 1 Experimental parameter setup

\begin{tabular}{ll}
\hline Tutting conditions & Levers \\
\hline Cutting speed $(\mathrm{m} / \mathrm{min})$ & $10,15,20,25$ \\
Depth of cut $(\mathrm{mm})$ & $0.05,0.1,0.15,0.2$ \\
Feed rate $(\mathrm{mm} / \mathrm{r})$ & $0.08,0.12,0.16,0.2$ \\
Amplitude of vibration $(\mu \mathrm{m})$ & $0,10,13,16,19$ \\
Frequency $(\mathrm{kHz})$ & 20 \\
\hline
\end{tabular}

\section{Results and discussion}

A comparison between the CT, UVAT, UEVT and 3D-UVAT methods was implemented. Fig. 11 are 2D micrograph of four turning methods, which were magnified two hundred times. As can be viewed, there are obvious irregular scratches and notches on the machined surface obtained by $\mathrm{CT}$. The reason for this phenomenon may be extrusion, bonding and wear between the turning tool and the workpiece. However, machined surface quality obtained by the other turning methods (UVAT, UEVT and 3D-UVAT) has been significantly improved. In other words, ultrasonic vibration assisted turning contributes to reducing machined surface defects. The reason for the improvement of machined surface quality is that compared with ordinary turning, ultrasonic vibration-assisted turning changes the turning mechanism. The contact between tool nose and workpiece has changed from continuous contact to intermittent contact. The reduction of contact time helps to reduce the cutting force and cutting heat, thereby reducing the friction between turning tool and workpiece, and weakening the bonding between turning tool and workpiece surface.

Although the machined surfaces obtained by several ultrasonic vibration-assisted turning methods are better than that of common turning, there are also obvious differences among several ultrasonic vibration-assisted turning methods. According to Fig. 11, compared with UVAT and UEVT, the material shedding and surface furrow of machined workpiece obtained by 3D-UVAT are significantly reduced. The reduction of these two aspects helps to reduce the roughness of machined surface. The reason for this phenomenon may be that during 3D-UVAT process, the turning tool trajectory is a 3D space curve that periodically changes in the directions of the $\mathrm{X}, \mathrm{Y}$ and $\mathrm{Z}$ coordinate axes. This special motion trajectory of turning tool will leave regular concaves on workpiece surface. These regular concaves help reduce the friction resistance of workpiece surface [30].

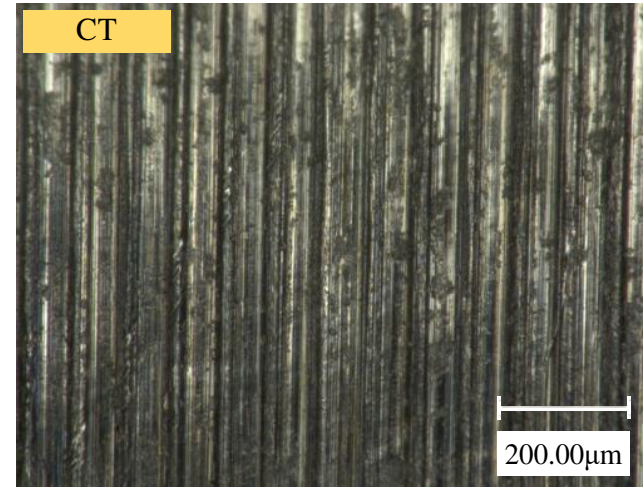

(a)

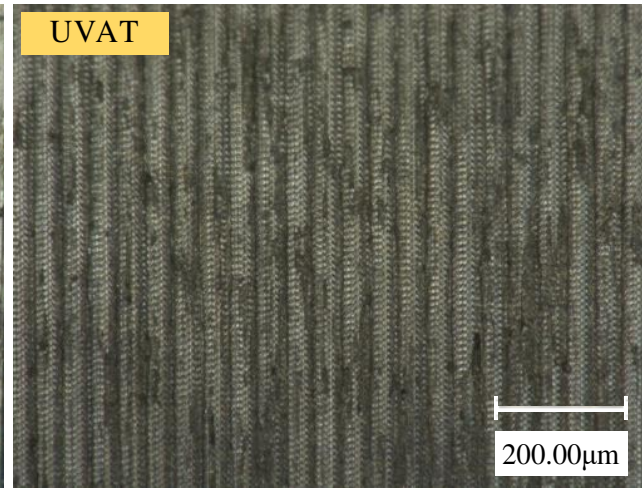

(b) 


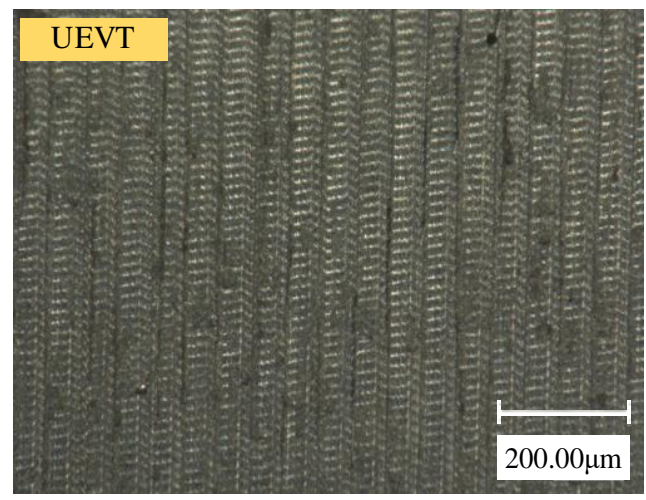

(c)

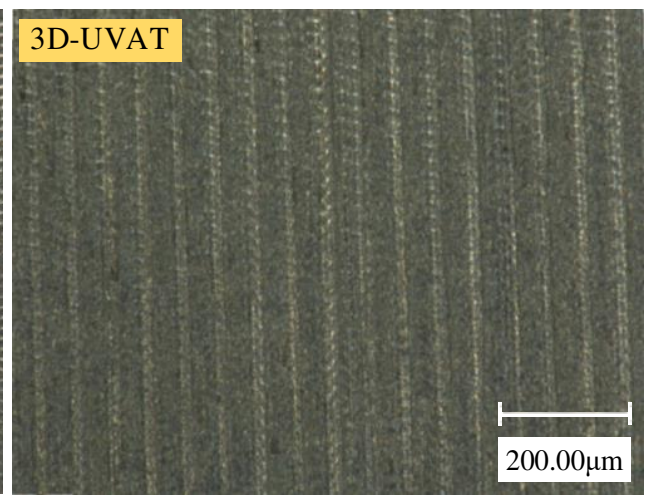

(d)

Fig. 11 2D micrographs of surfaces obtained by four turning methods

The three-dimensional surface topographies measured by the 3D surface profiler are shown in Fig. 12. In the figure, there is a selection of several surface topography pictures from the experimental results. Fig. 12(a) is the three-dimensional topography of machined surface obtained by CT when the $v_{c}=10 \mathrm{~m} / \mathrm{min}, a_{p}=0.05 \mathrm{~mm}, f_{r}=0.08 \mathrm{~mm} / \mathrm{r}$. Deep furrows are distributed on the machined surface in Fig. 12(a). The height of peak-valley is about $15.1 \mu \mathrm{m}$, which is greater than that obtained by the other three turning methods. Fig. 12(b) is the three-dimensional topography of machined surface obtained by UVAT when the $v_{c}=20 \mathrm{~m} / \mathrm{min}, a_{p}=0.05 \mathrm{~mm}, f_{r}=0.08 \mathrm{~mm} / \mathrm{r}, \mathrm{A}=19 \mu \mathrm{m}$. It is observed that the peak-valley of machined surface obtained by UVAT is about $13.0 \mu \mathrm{m}$. There are still furrows on the machined surface, but the width of furrows is narrower than that of CT. Fig. 12(c) is the three-dimensional topography of machined surface obtained by UEVT when the $v_{c}=25 \mathrm{~m} / \mathrm{min}, a_{p}=0.05 \mathrm{~mm}, f_{r}=0.08 \mathrm{~mm} / \mathrm{r}, \mathrm{A}=13 \mu \mathrm{m}$. Fig. 12 (c) shows that the machined surface obtained by UEVT is better than the above two turning methods. The advantages are mainly reflected in fewer furrows, shallower furrow depth and narrower furrow width. Fig. 12(d) is the threedimensional topography of machined surface obtained by $3 \mathrm{D}-\mathrm{UVAT}$ when the $v_{c}=25 \mathrm{~m} / \mathrm{min}$, $a_{p}=0.1 \mathrm{~mm}, f_{r}=0.08 \mathrm{~mm} / \mathrm{r}, \mathrm{A}=16 \mu \mathrm{m}$. Under this turning condition, the machined surface peak-valley height is $5.7 \mu \mathrm{m}$, which is less than the other three turning methods. According to Fig. 12(d), we can observe that the workpiece surface obtained by 3D-UVAT not only has no furrow, but also has uniform peak height distribution. In sum, among several turning methods, the 3D-UVAT has obvious advantages in improving the machined surface quality.

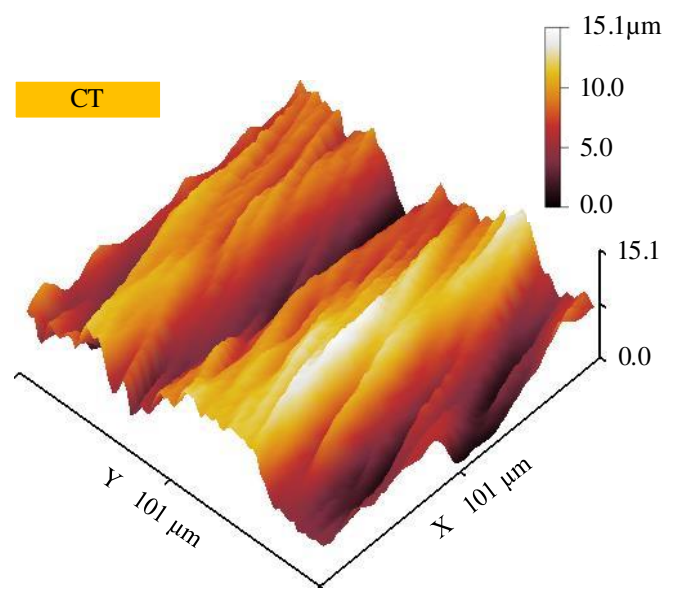

(a)

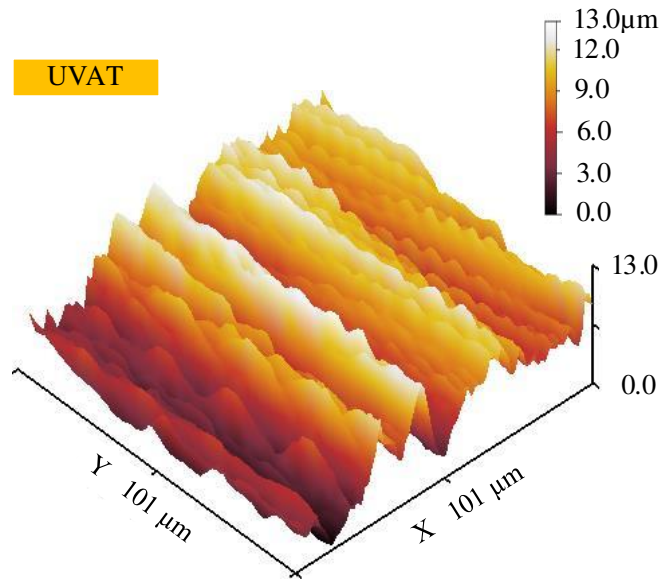

(b) 


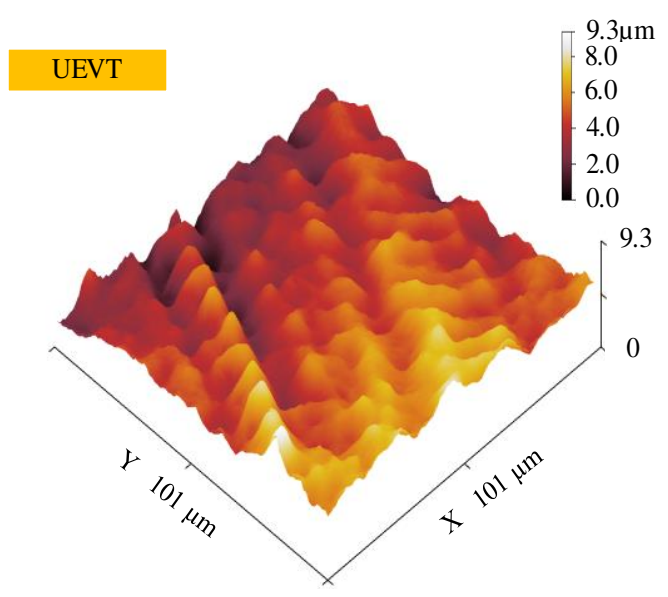

(c)

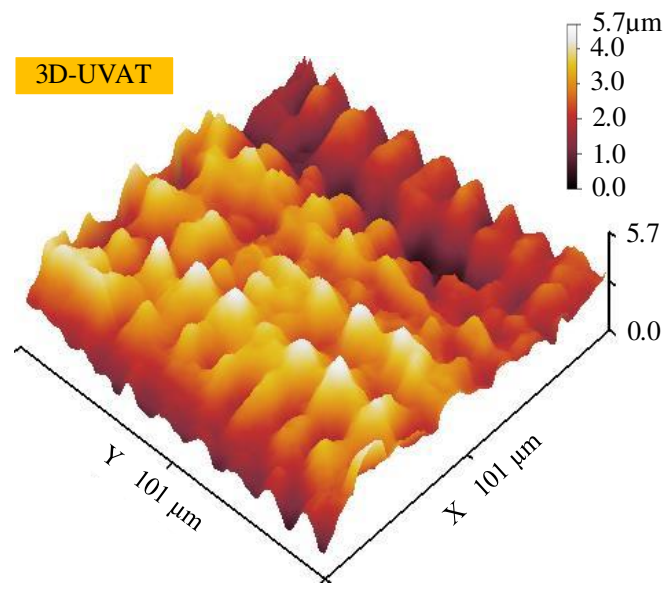

(d)

Fig. 12 Topography of surfaces obtained by four turning methods

The surface morphology of machined workpiece is three-dimensional. Therefore, it is more reasonable to use three-dimensional evaluation parameters to evaluate the machined surface. There are many three-dimensional evaluation parameters, of which the $S_{a}$ (Arithmetic mean deviation of 3D surface topography) is the most common [31]. Fig. 13 shows the $S_{a}$ of machined surface obtained by CT, UVAT, UEVT, and 3D-UVAT.

$$
S_{a}=\frac{1}{l_{x} l_{y}} \int_{0}^{l_{x}} \int_{0}^{l_{y}}|\eta(x, y)| d x d y \approx \frac{1}{M N} \sum_{j=1}^{N} \sum_{i=1}^{M}\left|\eta\left(x_{i}, y_{j}\right)\right| d x d y
$$

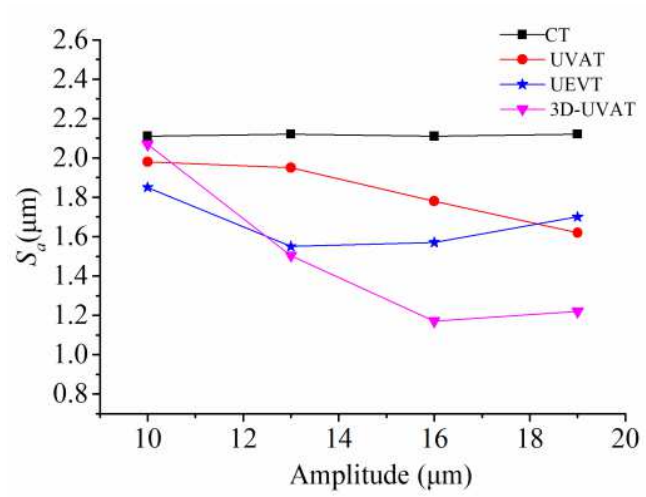

(a)

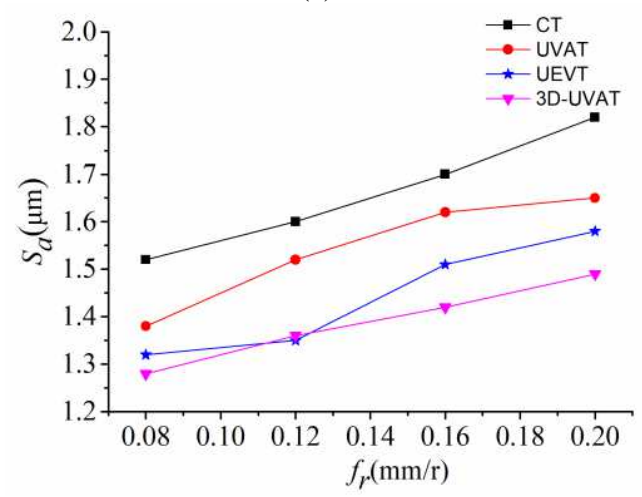

(c)

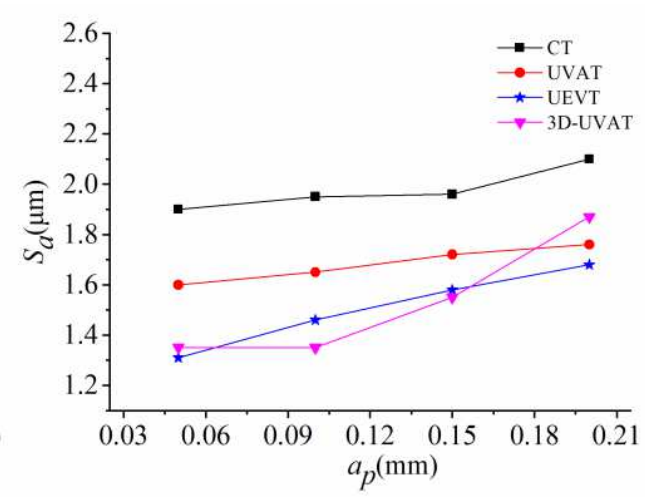

(b)

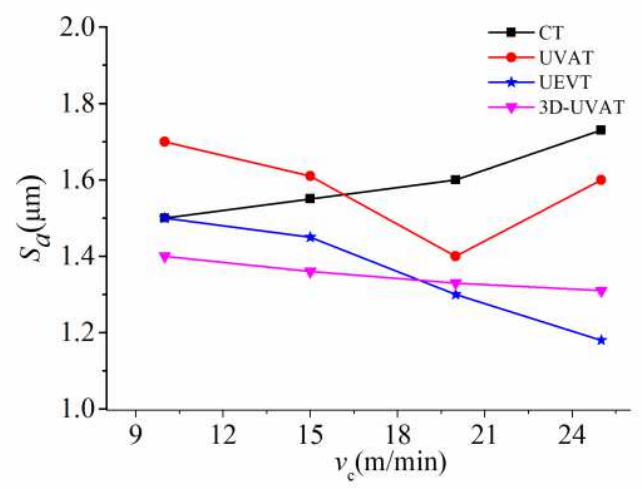

(d)

Fig. 13 The relationship between surface roughness and ultrasonic amplitude

According to Fig. 13, compared with CT, the UVAT, UEVT, and 3D-UVAT can significantly reduce the roughness of machined surface. In Fig. 13(a), the graph shows the relationship between $S_{a}$ and ultrasonic amplitude. With the increase of ultrasonic amplitude, the $S_{a}$ decreases at first and 
then increases during the 3D-UVAT process. When the ultrasonic amplitude is greater than $16 \mu \mathrm{m}$, the surface roughness obtained by 3D-UVAT is lower than other turning methods. However, ultrasonic amplitude is $10 \mu \mathrm{m}$, the surface roughness of 3D-UVAT is close to CT. In other words, within a certain ultrasonic amplitude range, the quality of machined surface increases with the increase of ultrasonic amplitude. But beyond the proper amplitude range, the quality of machined surface will decrease. Therefore, during the ultrasonic vibration-assisted turning process, the appropriate amplitude contributes to improving the machined surface quality.

In Fig. 13(b), there is a graph of the relationship between $S_{a}$ and $a_{p}$. We can get that the roughness of machined surface obtained by UEVT and 3D-UVAT increases with the value of $a_{p}$. However, during CT and UVAT processes, the effect of $a_{p}$ on surface roughness is shallow. When the $a_{p}$ is $0.06 \mathrm{~mm} \sim 0.15 \mathrm{~mm}$, 3D-UVAT has more obvious advantages than UEVT in terms of machined surface quality. However, if the $a_{p}$ is greater than $0.18 \mathrm{~mm}$, the quality of 3D-UVAT will drop sharply.

Fig. 13(c) shows that, compared with other turning methods, 3D-UVAT can obtain better surface quality during the turning process. In-depth study the curve can be found that as $f_{r}$ increases, the surface quality decreases. The reason for this phenomenon may be that as the $f_{r}$ increases, the turning area in unit time increases, resulting in an increase in turning deformation and plastic side flow.

In Fig. 13(d), compared with CT and UVAT, the 3D-UVAT method can achieve better surface quality, within the range of experimental conditions. The curves of UEVT and 3D-UVAT show that the greater the $v_{c}$, the smaller the $S_{a}$. When $v_{c}$ is lower than $18 \mathrm{~m} / \mathrm{min}, 3 \mathrm{D}-\mathrm{UVAT}$ can obtain better quality compared with UEVT. Out of the blue, if the amplitude exceeds $20 \mu \mathrm{m}$, compared with UEVT, 3D-UVAT can obtain a better machined surface.

\section{Conclusion}

In this paper, based on the theoretical analysis of several turning methods, a novel 3D-UVAT driven by a single actuator was developed. Simulation and experimental results prove the feasibility of the 3D-UVAT device. The conclusions of the above work are summarized as follows:

(1) Theoretical analysis of machined surface. The machined surfaces obtained by four turning methods are compared from peak-valley height and bulge width. According to the equation, the peak-valley height of machined surface obtained by 3D-UVAT is smaller than CT and UEVT. Compared with UVAT, the surface bulge width obtained by 3D-UVAT is finer. It shows that the 3DUVAT method is feasible.

(2) The key part of 3D-UVAT device is simulated by finite element method. The finite element analysis results show that, within the range of simulation parameters, the turning tool nose produces significant displacement in three coordinate axis directions. Under this premise, the maximum stress is less than permissible stress. The simulation results prove that this 3D-UVAT device is positive.

(3) A series of experiments are conducted to verify the performance of 3D-UVAT device. Compared with CT, UVAT and UEVT, the peak-valley height on machined surface obtained by 3DUVAT is the smallest. This is consistent with the results of theoretical analysis in this paper. Thus, this 3D-UVAT device has greater potential in improving the quality of machined surface.

\section{Reference}

1. Shamoto E, Moriwaki T (1994) Study on Elliptical Vibration Cutting. CIRP Ann 43:35-8. https://doi.org/https://doi.org/10.1016/S0007-8506(07)62158-1.

2. Tang J, Zhao B (2015) Study on a new type of longitudinal-torsional composite ultrasonic vibration system. J. Vib. Shock 34:57-61, 71.

3. Sajjady SA, Amini S (2019) Invention of a new ultrasonic horn in 3D ultrasonic vibration 
assisted turning. Modares Mech Eng 19:1845-54. http://mme.modares.ac.ir/article-15-22508en.html.

4. Ahmed N, Mitrofanov A V, Babitsky VI, Silberschmidt V V (2007) 3D finite element analysis of ultrasonically assisted turning. Comput Mater Sci 39:149-54. https://doi.org/https://doi. org/10.1016/j.commatsci.2005.12.045.

5. Sajjady SA, Nouri Hossein Abadi H, Amini S, Nosouhi R (2016) Analytical and experimental study of topography of surface texture in ultrasonic vibration assisted turning. Mater Des 93:311-23. https://doi.org/https://doi.org/10.1016/j.matdes.2015.12.119.

6. Ying Z, Shu L, Sugita N (2020) Experimental and finite element analysis of force and temperature in ultrasonic vibration assisted bone cutting. Ann Biomed Eng 1-10. https://doi.org/10.1007/s10439-020-02452-w

7. Shamoto E, Suzuki N, Hino R (2008) Analysis of $3 \mathrm{D}$ elliptical vibration cutting with thin shear plane model. CIRP Ann 57:57-60. https://doi.org/https://doi.org/10.1016/j.cirp.2008.03.073.

8. Wang H, Hu Y, Cong W, Hu Z, Wang Y (2020) A novel investigation on horizontal and 3D elliptical ultrasonic vibrations in rotary ultrasonic surface machining of carbon fiber reinforced plastic composites. J Manuf Process 52:12-25. https://doi.org/https://doi.org/10. 1016/j.jmapro.2020.01.027.

9. Chen J, Lu M, Lin J, Zhou J, Fu X, Zhou X (2021) Non-resonant 3D Elliptical Vibration Cutting Induced Submicron Grating Coloring. Int J Precis Eng Manuf 22:659-69. https://doi.org/10. 1007/s12541-021-00470-09.

10. Usman MM, Zou P, Ji B, Lin T (2021) Development of empirical models for the prediction of surface functional parameters in ultrasonic elliptical vibration cutting. Int J Adv Manuf Technol 113:2575-94. https://doi.org/10.1007/s00170-021-06811-2.

11. Lu K, Tian Y, Liu C et al (2020) Design of a novel 3D ultrasonic vibration platform with tunable characteristics. Int J Mech Sci 186:105895. https://doi.org/https://doi.org/10.1016/j. ijmecsci.2020.105895.

12. Lotfi M, Amini S, Akbari J (2020) Surface integrity and microstructure changes in $3 D$ elliptical ultrasonic assisted turning of Ti-6Al-4V: FEM and experimental examination. Tribol Int 151:106492. https://doi.org/https://doi.org/10.1016/j.triboint.2020.106492.

13. Wang $\mathrm{G}$ (2019) The design and research of a three-dimensional ultrasonic vibration machining device. Dissertation, Jilin University.

14. Wang X (2019) The design and research of a three-dimensional ultrasonic vibration machining device. Dissertation, Tianjin University of Technology.

15. Lin J, Lu M, Zhou X (2016) Development of a non-resonant 3D elliptical vibration cutting apparatus for diamond turning. Exp Tech 40:173-83. https://doi.org/https://doi.org/10. 1111/ext.12051.

16. Lu M, Zhou J, Lin J, Gu Y, Han J, Zhao D (2017) Study on Ti-6Al-4V alloy machining applying the non-resonant three-dimensional elliptical vibration cutting. Micromachines 8:306. https://doi.org/https://doi.org/10.3390/mi8100306.

17. Song Y (2017) Research and development of 3D elliptical vibration assisted cutting system[dissertation]. Nan jing: Nanjing University of Aeronautics and Astronautics; 2017.

18. Lin J, Han J, Lu M, Zhou J, Gu Y, Jing X, Feng D (2017) Design and performance testing of a novel three-dimensional elliptical vibration turning device. Micromachines 8:305. https://doi.org/https://doi.org/10.3390/mi8100305. 
19. Cui X (2012) Research on three-dimensional ultrasonic vibration cutting technology. Dissertation, Northeastern University.

20. Lu M (2019) Development of 3D elliptical vibration assisted cutting apparatus and its control. Dissertation, Jilin University.

21. Kurniawan R, Ali S, Park KM, Li CP, Ko TJ (2019) Development of a three-dimensional ultrasonic elliptical vibration transducer (3D-UEVT) based on sandwiched piezoelectric actuator for micro-grooving. Int J Precis Eng Manuf. 20:1229-40. https://doi.org/https://doi. org/10. 1007/s12541-019-00126-9.

22. Hosseinabadi HN, Sajjady SA, Amini S (2018) Creating micro textured surfaces for the improvement of surface wettability through ultrasonic vibration assisted turning. Int J Adv Manuf Technol 96:2825-2839. https://doi.org/https://doi.org/10.1007/s00170-018-1580-2.

23. Shu R (2008) Design and calculation method of non-circular section steel wire cylindrical helical compression spring. Mach. Ind. Standardization Qual 23: 21-25. Chinese.

24. Liu H (2000) Mechanics of materials. 4th ed. Higher Education Press: Beijing; 2000.

25. He Y (2018) Theoretical and experimental investigations on circular flexure hinge-based vibration assisted cutting apparatus. Dissertation, Northeastern University.

26. Davinci MA, Parthasarathi NL, Borah U, Albert SK (2014) Effect of the tracing speed and span on roughness parameters determined by stylus type equipment. Measurement 48:368-77. https://doi.org/https://doi.org/10.1016/j.measurement.2013.11.023.

27. Jamshidi H, Nategh MJ (2013) Theoretical and experimental investigation of the frictional behavior of the tool-chip interface in ultrasonic-vibration assisted turning. Int J Mach Tools Manuf 65:1-7. https://doi.org/https://doi.org/10.1016/j.ijmachtools.2012.09.004.

28. Zhao H (2019) Theoretical and experimental investigations on ultrasonic elliptical vibration turning of nickel-based superalloy. Dissertation, Northeastern University.

29. Usman MM, Zou P, Tian Y, Wang W (2020) Experimental investigation on surface functional indices in Ultrasonic Elliptical Vibration Cutting of C45 carbon steel. Int J Adv Manuf Technol 109:187-200. https://doi.org/https://doi.org/10.1007/s00170-020-05661-8.

30. Tao G (2016) Study on the forming mechanism and surface properties of ultrasonic vibration assisted milling for squamous surfaces. Dissertation, Shandong University.

31. Xu Y (2016) Theoretical and Experimental investigations on ultrasonic vibration assisted turning of difficult-to-cut materials. Dissertation, Northeastern University.

Acknowledgement The authors are grateful for the financial support received from the National Natural Science Foundation of China.

Funding This project was supported by the National Natural Science Foundation of China (Grant No. 51875097).

Competing interests The authors declare no competing interests. 